\title{
Caminhos de uma antropologia urbana
}

Trajetória e projeto nos primeiros escritos de Gilberto Velho

Paths of an Urban Anthropology: the early writings of Gilberto Velho

\section{Julia O'Donnell}

\section{(2) OpenEdition}

\section{Journals}

Edição electrónica

URL: http://journals.openedition.org/aa/502

DOI: 10.4000/aa.502

ISSN: 2357-738X

\section{Editora}

Programa de Pós-Graduação em Antropologia Social (UnB)

\section{Edição impressa}

Data de publição: 31 dezembro 2013

Paginação: 37-51

ISSN: 0102-4302

\section{Refêrencia eletrónica}

Julia O'Donnell, «Caminhos de uma antropologia urbana», Anuário Antropológico [Online], v.38 n.2 |

2013, posto online no dia 01 fevereiro 2014, consultado o 28 abril 2021. URL: http://

journals.openedition.org/aa/502 ; DOI: https://doi.org/10.4000/aa.502

Este documento foi criado de forma automática no dia 28 abril 2021.

\section{(c) (i) (9)}

Anuário Antropológico is licensed under a Creative Commons Atribuição-Uso Não-Comercial-Proibição de realização de Obras Derivadas 4.0 International. 


\title{
Caminhos de uma antropologia urbana
}

\author{
Trajetória e projeto nos primeiros escritos de Gilberto Velho \\ Paths of an Urban Anthropology: the early writings of Gilberto Velho
}

\section{Julia O’Donnell}

\section{NOTA DO EDITOR}

Recebido em 30/09/2013

Aceito em 14/11/2013

1 No segundo semestre de 1969, o recém-criado Programa de Pós-Graduação em Antropologia Social do Museu Nacional (UFRJ) ${ }^{1}$ ofereceu aos seus alunos aquele que seria seu primeiro curso de Antropologia Urbana. A disciplina seria ministrada pelo norte-americano Anthony Leeds, então professor do Departamento de Antropologia da Universidade do Texas, que chegara ao PPGAS através de um convênio com a Fundação Ford. Ex-aluno da Universidade de Columbia, Leeds viera ao Brasil na década de 1950, interessado no estudo da plantation no sul da Bahia. Não tardou, contudo, para que seu olhar se voltasse para o universo das favelas brasileiras, tema que o acompanhou por longos anos e que o fez mergulhar no grande campo dos estudos urbanos. ${ }^{2}$ Num cenário de recrudescimento das políticas habitacionais na América Latina, Leeds viu nas favelas um campo privilegiado para o desenvolvimento de uma pesquisa qualitativa de fôlego, abrindo um campo de reflexão até então muito pouco explorado pelas ciências sociais brasileiras.

2 Em meio a uma esmagadora maioria de cursos voltados para os temas tradicionais da Antropologia clássica, ${ }^{3}$ os alunos inscritos na nova disciplina se deparavam com um pesquisador especialmente interessado na temática da habitação urbana, e que tinha em seu horizonte de análise a questão mais ampla das formas de relacionamento "dentro e entre diferentes categorias sociais" (Velho, 2011:161). As discussões e as 
leituras conduzidas por Anthony Leeds no decorrer do semestre resultaram, como é de praxe, na elaboração de trabalhos finais por parte dos alunos, que deveriam apresentar reflexões que tivessem como eixo o tema da habitação.

3 Yvonne Maggie e Gilberto Velho, então recém-casados, apresentaram uma pesquisa cujo objeto era, no mínimo, curioso: um prédio de pequenos apartamentos em Copacabana, habitado por pessoas da baixa classe média. Não se tratava, por certo, de um edifício qualquer. Notório por sua presença contínua nas páginas policiais e símbolo inconteste da precariedade urbana, o Barata Ribeiro $200^{4}$ abrigava cerca de 2 mil moradores, reunindo em seus 12 andares uma enorme variedade de pessoas em termos etários, sociais e ocupacionais.

4 Apesar de feito a partir de uma amostra relativamente pequena (foram 29 entrevistados), o texto não se furta de apresentar dados detalhados da estrutura física e organizacional do edifício, bem como uma análise cuidadosa do perfil socioeconômico de seus moradores. Em 16 páginas, os jovens antropólogos apresentaram a Anthony Leeds uma verdadeira descrição densa do edifício que dava nome ao trabalho, partindo da premissa de que o objeto escolhido era capaz de revelar "alguns aspectos interessantes" da ideologia das camadas médias urbanas.

5 Entre tais aspectos está, conforme destacado pelos autores, a ambivalência permanente entre o desejo de acesso a bens de consumo e a precariedade de suas habitações. Divididos entre a possibilidade (ainda que muito limitada) de gozo dos bens oferecidos pela sociedade urbana industrial e a angústia de viver em apartamentos mínimos num edifício de má fama, os moradores do Barata Ribeiro 200 acabavam por acionar um discurso que tinha na ideia um tanto vaga de status seu principal alicerce. Copacabana aparecia ali, a despeito de qualquer correspondência com a realidade material dos entrevistados, como a prova definitiva de sua ascensão social.

o texto não é ambicioso, nem tampouco ingênuo. Ainda que reconheçam o caráter "superficial e impressionista" da pesquisa, Yvonne e Gilberto deixam claro ter consciência da amplitude e da complexidade do fenômeno evidenciado pelo estudo de caso do Barata Ribeiro 200. Apresentado como "caso limite" de uma situação que se espraiava por diversos pontos da zona sul carioca, o edifício não é, em nenhum momento, tratado como uma realidade insular. Ao contrário, suas peculiaridades são vistas como resultado de um processo que envolve variáveis como migração, estratificação social, delinquência e discriminação, temas que se sobrepõem em muitas das questões tangenciadas no decorrer do trabalho.

7 A leitura do texto não estaria completa sem os comentários anexados por Anthony Leeds na tarefa de avaliar o trabalho feito pelo "casal antropológico". Destacando as dificuldades do campo escolhido, Leeds ressalta o talento e a habilidade de seus alunos como pesquisadores, bem como a qualidade da descrição apresentada. Por outro lado, identifica no texto aquilo que define como a ausência de uma orientação teórica, o que se refletiria, por exemplo, na falta de um título para o texto. "Por que o estudo? o que ele pretendia mostrar?", são as perguntas feitas pelo professor.

8 Ao que parece, as perguntas não passaram despercebidas pelo jovem Gilberto Velho. Conforme relatou anos mais tarde (Castro, Oliveira \& Ferreira, 2001), o entusiasmo provocado pela pesquisa feita em parceria com Yvonne precipitou definitivamente a escolha do tema de sua dissertação de mestrado. Ampliando o escopo da observação e das entrevistas para outros edifícios semelhantes em Copacabana, não demorou para 
que o trabalho ganhasse vulto e aporte analítico. Poucos meses depois, nascia A utopia urbana.

Publicado pela primeira vez em 1973, A utopia urbana é uma versão pouco modificada da dissertação de mestrado que Gilberto defendeu em 1970. Ainda que bastante fiel à versão original, já na primeira página do livro somos alertados para o fato de que é fruto da feliz combinação entre duas experiências acadêmicas: os dezoito meses do mestrado e a temporada de um ano no Departamento de Antropologia da Universidade do Texas, ao longo da qual Gilberto declara ter travado contato "com vários trabalhos em andamento sobre o meio urbano e sociedades complexas" (1973:1).

O livro é pequeno. As 99 páginas da primeira edição (incluindo a bibliografia) são uma verdadeira exceção em meio à tradição antropológica, feita de monografias extensas e publicações - literalmente - de peso. A impressão de modéstia que o volume provoca à primeira vista não resiste, contudo, à primeira frase com que se depara o leitor: "Pretendo, com este livro, dar início a uma série de trabalhos sobre o meio urbano, com uma abordagem antropológica".

11 Para além do anúncio precoce de trabalhos futuros, chama a atenção nesta frase tão simples quanto paradigmática a segurança e a certeza com que Gilberto se situava no campo da Antropologia Urbana. "E qual a novidade?", perguntaria, talvez, um aluno de hoje, habituado desde os primeiros tempos da graduação a ver a cidade como um objeto natural de exploração etnográfica. A resposta vem aos poucos para aqueles que seguem a leitura. Já na terceira página do livro, por exemplo, antes mesmo de qualquer apresentação da pesquisa, deparamo-nos com a seguinte declaração: "Morei dezoito anos em Copacabana". ${ }^{5}$ À referência biográfica se soma, em seguida, um claro posicionamento epistemológico: "A Antropologia, tradicionalmente, tem estudado os 'outros' e eu me propus a estudar o 'nós”' (:3).

12 Por "tradicionalmente", neste caso, podemos tomar quase tudo (para não dizer tudo) que havia sido feito até então na Antropologia brasileira. Como diz a seguir o próprio Gilberto, claramente consciente do passo que se propunha a dar com esse trabalho, a Antropologia Urbana ainda engatinhava naquele momento, enfrentando "sérios problemas de metodologia". o terreno era, nas suas palavras, "movediço". Enquanto o investigador dedicado às sociedades tribais ou camponesas encontrava a seu dispor um conjunto já consagrado de dados empíricos e suportes teóricos, ao pesquisador interessado no meio urbano restavam, como bem define Gilberto, a intuição, a polêmica e a escassez absoluta de resultados com os quais dialogar.

13 Mais do que uma questão de fidelidade fetichista a determinados temas e objetos, aquele panorama era para ele resultado de uma das coisas que procurou combater ao longo de toda a sua carreira: o provincianismo disciplinar. Ao lidar com uma escala de análise mais ampla, o pesquisador da cidade enfrentaria coisas como amostragem, estatísticas e tantas outras nomenclaturas caras ao métier do sociólogo. "E daí?", perguntava-se Gilberto, sempre incomodado diante da resistência ao uso combinado daquilo que chamava diferentes tradições de trabalho. Mas tal postura não indicava, sob nenhum aspecto, uma renúncia às especificidades e aos encantos da Antropologia. Pelo contrário. Sua postura defendia que uma boa antropologia se fazia de diálogos - fossem eles com nativos, fossem com outros campos de trabalho.

Em A utopia urbana essa postura é muito clara. As estatísticas convivem harmoniosamente com um exercício constante de produção de alteridade, numa equação em que o distanciamento do pesquisador é permeado com frequência pela 
lembrança daquela lição que Max Weber já anunciara nos primórdios da ciência da sociedade: o pesquisador e seu objeto partilham da mesma natureza social. Seja na esquina de sua casa ou numa tribo longínqua, o distanciamento não é um dado objetivo, e sim uma construção intelectual. ${ }^{6}$

Mas vamos à pesquisa. A Copacabana encontrada por Gilberto no final da década de 1960 era, em muitos sentidos, o retrato mais bem acabado do caos. Com mais de $250 \mathrm{mil}$ habitantes ${ }^{7}$ ocupando um território de $5 \mathrm{~km}^{2}$, o bairro tinha uma rotina pontuada por problemas de circulação e de higiene, num cenário que pouco remetia aos padrões clássicos de status e prestígio que haviam transformado o bairro no mais famoso cartãopostal do país nas décadas anteriores. ${ }^{8}$ Num cenário marcado pela hegemonia do concreto, $98,8 \%$ das moradias eram apartamentos, e a densidade populacional era das mais altas do mundo. Apesar disso, o bairro seguia recebendo moradores de outras regiões e cidades, que muitas vezes deixavam boas casas em seus locais de origem para viver em apartamentos de um ambiente com pouco mais de $20 \mathrm{~m}^{2}$ em Copacabana. Diante disso, Gilberto fez a mais simples das perguntas: por quêe?

Aqui, mais uma vez, pesquisador e objeto se encontram. Animado com as perspectivas analíticas abertas em sua breve incursão ao Barata Ribeiro 200, Gilberto viu no próprio edifício em que vivia a possibilidade de um campo privilegiado. Construído no final da década de 1950, o Edifício Estrela (nome fictício) abrigava cerca de 450 pessoas distribuídas em 176 apartamentos de $39 \mathrm{~m}^{2}$. Separadas por paredes finas e estreitas, as unidades não primavam pela privacidade. Tal cenário punha em constante negociação pessoas de diferentes gerações, hábitos e ocupações, num ambiente de conflito latente. Não bastasse a precariedade material, o Estrela amargava ainda a fama de reunir habitantes considerados de "baixo padrão moral" (1973:34), como prostitutas, marginais e homossexuais. Como ele mesmo recordaria anos mais tarde, nascia ali seu interesse por dinâmicas marcadas pela acusação e pelo desvio, temáticas que seriam mais bem desenvolvidas na sua tese de doutorado, Nobre e anjos - um estudo de tóxicos $e$ hierarquia, defendida em 1975.

do de três variáveis fundamentais (estratificação social, residência e ideologia), a pesquisa valeu-se também de entrevistas feitas com moradores de outras partes do bairro, de modo a responder quem eram, afinal, aquelas pessoas que viam em Copacabana um verdadeiro Eldorado a redimir suas suburbanas biografias.

Gilberto se deparava, então, com aquele que seria seu companheiro de toda uma vida: o universo das camadas médias urbanas. Se no trabalho entregue a Anthony Leeds a pesquisa parecia ainda carecer de um objeto de análise bem definido, agora seus "nativos" se apresentavam de forma muito mais clara. Inspirado pela leitura de grandes clássicos da antropologia, o jovem pesquisador entrava em campo decidido a compreender os setores médios da sociedade brasileira através de um olhar que lhe permitisse ir além das informações trazidas pelos tradicionais questionários e dados estatísticos. ${ }^{9}$

19 Ainda que neste livro trabalhe com a categoria white-collar (emprestada de Wright Mills), ${ }^{10}$ estão ali muito claras e de forma mais ampla as bases de seu fascínio pela visão de mundo (Geertz, 1989) ${ }^{11}$ de setores médios da sociedade, que até então não faziam parte do rol de temas legitimados pela antropologia, não apenas no Brasil, mas também em termos internacionais. Gilberto defendia sua escolha um tanto herética afirmando que era necessário aproximar-se das camadas médias com outro olhar, indo além da explicação mecânica de que ficavam entre a classe operária e as oligarquias. Era preciso 
entendê-las em sua complexidade, em sua heterogeneidade, em seus vários estilos de vida.

É importante lembrar também que o contexto político-histórico em que Gilberto iniciou sua trajetória intelectual foi determinante na construção de seu interesse por aquele universo social específico. Afinal, com a implantação do regime militar em 1964, determinados setores das camadas médias assumiram relativo protagonismo no apoio à nova ordem política, e era preciso entender o que se passava. Copacabana despontava, naquele cenário, como universo privilegiado de pesquisa àquelas indagações. Local de moradia de famílias pertencentes a uma classe média superior, mas também de pessoas ligadas a camadas mais baixas, o bairro reunia, de forma muito particular, os vários setores que compunham as camadas médias urbanas brasileiras. Nas palavras do próprio Gilberto,

[...] em 31 de março [de 1964, data da tomada do poder pelos militares], quando puseram fogo na UNE, ${ }^{12}$ voltei para casa caminhando e, quando cheguei a Copacabana, vi que havia uma enorme festa. Fiquei realmente muito curioso e impressionado. Eu sei que também havia gente trancada dentro de casa, lamentando, mas na rua havia aquela grande festa, e eu queria saber quem eram aquelas pessoas, por que elas pensavam daquele jeito, por que estavam fazendo aquela escolha. [...] eu tinha interesse, até por uma motivação política, em entender por que as pessoas das camadas médias urbanas tomavam as posições que tornavam. Quem eram aquelas pessoas? Como era a sua vida? Qual era a sua visão de mundo? Qual era a sua ideologia, ou quais eram as suas ideologias? Na realidade, eu me convenci de que estudar isso era uma tarefa fundamental (Castro, Ferreira \& Oliveira, 2002:191).

21 Ao buscar compreender as motivações que levavam donas de casa, comerciários, estudantes e pequenos funcionários públicos a morarem no bairro, Gilberto deparou-se com o que chamou de "o motor da ideologia copacabanense": a ideia de que o bairro era o locus das coisas boas da vida, numa definição que reunia critérios como abundância de comércio e de divertimentos, além de constantes referências à noção de acesso ao mundo da "modernidade". A chegada a Copacabana era então associada à sensação inequívoca de triunfo, num discurso guiado pela premissa da mobilidade social, mesmo que pontuado pela consciência da precariedade das condições de moradia. Ainda que não empregue estas palavras no livro, surgiam ali, muito claramente, as ideias de projeto e de campo de possibilidades - outros fiéis companheiros de Gilberto ao longo de toda a sua trajetória. Definida por Alfred Schutz (1979) como "conduta organizada para atingir finalidades específicas", a noção de projeto lida diretamente com a dimensão do indivíduo-sujeito, servindo como instrumento privilegiado à análise de trajetórias coletivas ou individuais, bem como à articulação de discursos identitários (Velho, 1994:101). O campo de possibilidades, por sua vez, corresponde ao espaço para formulação e implementação dos projetos, correspondendo às opções "construídas dentro do processo sócio-histórico e com o potencial interpretativo do mundo simbólico da cultura" (Velho, 1994:28). ${ }^{13}$

22 Num olhar retroativo, fica claro que para muitos dos moradores do Estrela mudar-se para Copacabana era um passo fundamental num projeto mais amplo de conquista da liberdade individual. Não uma liberdade qualquer, mas a liberdade do anonimato, conforme atestam depoimentos reproduzidos no livro:

Adoro Copacabana. Ninguém se mete na vida de ninguém. Que eu tenho a ver com a vida dos outros? (Velho, 1973:26).

O movimento, a beleza, a gente faz o que quer. Ninguém conhece ninguém e todo 
mundo conhece todo mundo (:29).

Gosto de saber que existem movimento e confusão na esquina de casa. Na hora que eu quiser, me perco nela (:57).

Machado da Silva e publicado no primeiro número do Anuário Antropológico, em 1977, sob o sugestivo nome de "Organização social do meio urbano". Ali, em meio a uma larga maioria de textos dedicados a temas clássicos da antropologia (como etnologia indígena e sociedades rurais), é possível ver ainda muito viva a preocupação dos autores em afirmar a legitimidade de uma antropologia urbana. Não por acaso, começam o texto afirmando o interesse em fazer ciência social $n a$ cidade e não $d a$ cidade, garantindo que suas perguntas na aproximação com o objeto não são diferentes daquelas feitas por pesquisadores de sociedades tribais ou camponesas: "Como se organizam essas pessoas? Como subsistem? Quais são seus objetivos? Quais são os símbolos que presidem seu comportamento? Quais são suas estratégias de vida? Como resolvem seus conflitos?" (Velho \& Silva, 1977:71). No mesmo sentido, insistem na desessencialização do "urbano" como uma realidade sui generis, advogando que a problemática da cidade deve ser analisada de forma integrada a processos sociais globais (79), de modo a deixar claro que a antropologia urbana não deveria, por seu objeto ou por seus procedimentos, ser tomada como um desvio na história da disciplina.

Por outro lado, é nítida a fluência com que são tratados temas que aparecem de forma ainda muito incipiente em A utopia urbana, como a problemática do individualismo e uma reflexão mais abrangente sobre a sociabilidade nas grandes cidades. Como mostram as muitas notas que acompanham o texto, tal fluência vinha em grande medida fiada pela ampliação dos diálogos teóricos dentro do campo dos estudos urbanos. O leitor se depara recorrentemente com nomes como Georg Simmel, Robert Park e Louis Wirth, autores que Gilberto Velho levaria com ele durante toda a sua trajetória, na tarefa incansável de refletir sobre as práticas sociais em curso nas grandes cidades.

É nesse cenário que surge, como ponto-chave da reflexão desenvolvida no texto, a ideia de anonimato relativo. Ainda que não seja apresentada como elemento da vida urbana per $s e$, a possibilidade de trânsito por diferentes meios sociais apareceria de forma mais intensa no tipo de organização socioespacial típico das grandes cidades. Nas palavras dos autores,

o que seria característico, então, da grande metrópole é a possibilidade de desempenhar papéis diferentes em meios sociais distintos, não coincidentes e, até certo ponto, estanques. Isto é o que seria o anonimato relativo (Velho \& Silva, 1976:80).

Em texto publicado em 2000, tais questões apareceriam de forma ainda mais clara e amadurecida nos termos das relações entre individualismo e metrópole. Ali, destacando a pluralidade de papéis que marca a vida das grandes cidades, Gilberto afirmava que

É o trânsito e a circulação entre diferentes grupos e meios sociais que é causa e consequência, num processo circular, de expansão dos valores individualistas. [...] 0 que seria característico, então, da grande metrópole é a possibilidade de 
desempenhar papéis diferentes em meios sociais distintos [...]. Isto é o que seria anonimato relativo (2000:19).

A questão do trânsito por diferentes mundos sociais e sua relação com o individualismo apontam para outro aspecto central da obra de Gilberto: a importância da ideia de heterogeneidade como elemento fundamental para a análise social em contexto urbano. Em A utopia urbana (e, de alguma maneira, também no texto sobre o Barata Ribeiro 200), isto aparece na insistência com que Gilberto resiste à tentação de tomar o conjunto dos habitantes do Estrela como um grupo. Não é outro o sentido da grande variedade de trajetórias ali reunidas, bem como do destaque dado aos inúmeros conflitos que marcavam o cotidiano dos moradores do edifício. Se, para muitos, a ausência de um grupo coeso era o calcanhar de Aquiles de uma pretensa antropologia urbana, esta era, para ele, justamente a sua riqueza.

Não era outra a razão para, já nas conclusões do livro, Gilberto enfrentar a questão de frente. "Até que ponto a Antropologia Social pode ser útil para a investigação do meio urbano?", pergunta ele. A resposta vem através da defesa de uma flexibilidade metodológica que considerasse as especificidades das sociedades complexas e, portanto, a impossibilidade de uma abordagem totalizante. A antropologia seria, assim, mais que um tributo fiel aos ensinamentos malinowskianos, uma forma de ver e entender o mundo, atenta às representações dos nativos, sua forma de organizar e classificar a sociedade em que vivem. À etnografia em meio urbano caberia, então, a busca pela lógica e pela coerência internas do discurso do universo pesquisado, numa pretensão que faz da observação participante condição sine qua non para que o investigador vá além das aparências, identificando códigos nem sempre explicitados.

Mas o livro tem também marcas do seu tempo. Para o leitor assíduo dos textos mais recentes de Gilberto, chega a ser estranho vê-lo insistir na discussão de termos como "estratificação" e "alienação", na clara tentativa de dialogar com as tradições marxistas - tão fortes, para não dizer hegemônicas, no momento da pesquisa. Não que Gilberto negasse a importância dos escritos de Marx em sua formação, ao contrário, gostava de situá-los ao lado da Escola de Chicago, da antropologia social britânica e da obra de Marcel Mauss como uma das principais influências em sua formação intelectual. Ainda que não se considerasse um marxista, defendia que questões como a estrutura de classes e a estratificação social eram de suma importância e absolutamente atuais, especialmente para pesquisadores atentos ao universo das sociedades complexas e das camadas médias urbanas. Advogava, contudo, pelo que chamava da flexibilização daquelas questões através do estabelecimento de "pontes com outros temas no nível de universos simbólicos, de sistemas culturais” (Castro, Ferreira \& Oliveira, 2001:200).

No memorial apresentado em 1992, no concurso de professor titular em Antropologia Social do Museu Nacional, Gilberto diz ver em A utopia urbana a forte presença de um pensamento sociológico de raízes marxistas, "embora dialogando com a Antropologia Social propriamente dita". Daquela equação surgia um trabalho cuja problemática básica era, nas suas palavras, "a relação entre experiência social e ideologia/ representação". ${ }^{14}$ Não é de estranhar, assim, que nas conclusões do livro, quando apresenta um diálogo mais direto com o universo temático e semântico do marxismo, Gilberto reafirme que sua preocupação era "escapar de uma análise reificante da vida de diferentes grupos situados especialmente em uma grande metrópole" (Velho, 1973:92), partindo, para tal, da premissa de que a complexificação das Ciências Sociais 
demandava a aceitação de diferentes "níveis de realidades correspondentes a diferentes apreensões individuais ou grupais de uma série de dados "brutos"' (1973).

Bem, lidas as conclusões, findo o livro, certo? Eu diria que não. Neste caso específico, entender a marca do trabalho demanda também uma visita às referências bibliográficas. Mas a visita é breve - afinal, trata-se de uma única página com apenas 15 obras listadas: quatro reportagens de jornal, um artigo do próprio Gilberto e apenas dez obras de cientistas sociais (Paul-Henri C. Lawe, Elizabeth Bott, Émile Durkheim, Raymond Firth, Ervin Goffman, C. Wright Mills, Luís Pereira e Clyde Mitchels). Se fosse hoje, tal economia pareceria pedantismo ou autismo intelectual. Era, na verdade, pioneirismo.

Como mostra a bibliografia enxuta, a pesquisa foi feita também em face do desafio de poder contar com poucos, bem poucos, interlocutores. Onde estão, por exemplo, Simmel e Schutz, duas referências centrais na obra de Gilberto? E Becker, Foote-White, Blummer, Roberto Park? São ausências que gritam no livro para quem aprendeu Antropologia Urbana lendo estes autores. Gilberto afirma que foi só na sua temporada nos Estados Unidos que passou a ter mais contato com a Escola de Chicago - nas suas muitas vertentes, como gostava de lembrar. Ainda que tivesse no Brasil aquilo que chamou de "algum contato" com a questão da cidade como fenômeno, foi apenas depois do mestrado que passou a se aprofundar em temas como o interacionismo, as trajetórias e a relação indivíduo/sociedade. Daí para a Simmel, Schutz e a Escola de Chicago foi um passo. E um caminho de ida sem volta.

Muito além de um capricho ou de um lampejo de exotismo, A utopia urbana era, como se vê, um movimento claro e consciente na direção da fundação de um campo de estudos. Um projeto, diria eu, nos termos do próprio Gilberto.

Ao leitor atento é impossível não perceber que por trás de cada número, de cada depoimento, de cada reflexão traçada por Gilberto em seu esforço de desnudar Copacabana estava posto o desafio centrífugo de compreensão das sociedades complexas; e que, ao lado dele, havia naquela etnografia um tanto herética para os padrões de seu tempo uma defesa apaixonada da Antropologia como visão de mundo. Afinal, segundo ele próprio,

Você não pode pensar a vida social e cultural simplesmente de modo abstrato, mas sim através da vida dos indivíduos, do dia a dia, do cotidiano, das decisões que os indivíduos tomam, das escolhas que não são livres em termos absolutos, mas que são feitas no que a gente chama de um campo de possibilidades, de um repertório sociocultural (Velho apud Santana \& Silva, 2006).

E como chegar até lá, senão pela Antropologia?

Nos dias de hoje, um livro descrito como um estudo sobre as camadas médias urbanas, feito a partir de observação participante num edifício do bairro de Copacabana, não despertaria qualquer espanto. Quiçá sequer interesse. Num universo intelectual aberto, para não dizer escancarado, ao estudo social em cenário urbano, tal trabalho soaria como mais um num vasto mundo de pesquisas que tomam como ponto de partida a premissa inabalável de que o "outro" pode estar ao lado. E que não só pode, como deve ser estudado com o mesmo rigor e interesse que uma tribo distante. Mas assim como seus objetos de estudo, também as Ciências Sociais são, elas mesmas, objeto de estranhamento e relativização. Por isso, tratar da naturalidade com que as grandes cidades transitam hoje pela Antropologia brasileira nas suas mais variadas formas e vertentes nos remete à necessidade de retomar o fio de sua história. 
E é justamente nesse exercício que reside a importância da publicação da pesquisa de Gilberto Velho e Yvonne Maggie sobre o Barata Ribeiro 200. Por muitos anos guardado - em sua versão original, entre os inúmeros papéis acumulados por Gilberto - o texto nos chega hoje com o frescor de uma novidade. Os mais de quarenta anos que separam a escrita do trabalho de sua publicação neste número do Anuário Antropológico não são, de forma alguma, testemunho de seu apagamento. Pelo contrário, fazem dele uma peçachave na importante tarefa de relativizar e historicizar a naturalidade com que a Antropologia Urbana é hoje vista como parte legítima e inconteste das Ciências Sociais no país. Para além de ousada etnografia feita em contexto urbano, o texto guarda em si o registro pulsante do pioneirismo de Gilberto Velho, abrindo não apenas o caminho intelectual do autor, como também (e sobretudo) os muitos caminhos que se ramificaram na forma de uma Antropologia Urbana no Brasil.

\section{BIBLIOGRAFIA}

ANTONIO, João. 2001. Ô Copacabana. São Paulo: Cosac \& Naify.

BASTOS, Cristiana \& CORDEIRO, Graça Índias. 1997. "Desafios e metamorfoses da Antropologia contemporânea: entrevista com Gilberto Velho”. Etnográfica, 1(2):321-327.

GEERTZ, Clifford. 2008. A interpretação das culturas. Rio de Janeiro: LTC.

CASTRO, Celso; FERREIRA, Marieta \& OLIVEIRA, Lucia Lippi. 2002. "Entrevista com Gilberto Velho". Revista Estudos Históricos, 2 (28): 183-210.

WRIGHT MILLS, C. 2001. White Collar: The American Middle Classes. Nova York: Oxford University Press.

O’DONNELL, Julia. 2013. A invenção de Copacabana. Rio de Janeiro: Jorge Zahar Editor.

SANTANA, Gisela Verri \& SILVA, Leonardo Cruz da. 2006. "Entrevista com Gilberto Velho". Revista Estudos e pesquisas em psicologia, 6(2):152-158.

VELHO, Gilberto. 1973. A utopia urbana. Rio de Janeiro: Jorge Zahar Editor.

. 1987. Individualismo e cultura. Rio de Janeiro: Jorge Zahar Editor.

. 1998. Nobres \& Anjos: um estudo de tóxicos e hierarquia. Rio de Janeiro: Ed. da FGV.

1994. Projeto e Metamorfose: antropologia das sociedades complexas. Rio de Janeiro: Jorge Zahar Editor.

. 2000. "Individualismo, anonimato e violência na Metrópole". Horizontes Antropológicos, 13:15-26.

VELHO, Gilberto \& Silva, Luiz Antonio Machado da. 1976. “Organização Social do meio urbano”. Anuário Antropológico, 1(1):71-82.

WEBER, Max. 1992. “A 'Objetividade’ do conhecimento na Ciência Social e na Ciência Política”. In: _-_. Metodologia das ciências sociais. São Paulo: Cortez. pp. 107-154. 


\section{NOTAS}

1. O PPGAS do Museu Nacional/UFRJ, criado em 1968, foi o primeiro programa de pós-graduação em Antropologia Social no país.

2. O resultado mais expressivo desse investimento é o livro Sociologia do Brasil urbano, de 1978, escrito em parceria com sua esposa, Elizabeth Leeds.

3. Em 1969, o PPGAS ofereceu as seguintes disciplinas aos seus alunos: Organização Social, Sociedades Campesinas, Desenvolvimento Regional Comparado, Ecologia Antropológica, Mobilização, Desenvolvimento e Subdesenvolvimento, Problems in Comparative Anthropolgy e Antropologia Urbana.

4. Mais conhecido como "Barata Ribeiro 200" ou como "Duzentão", o Edifício Richard foi construído em 1959, com 300 apartamentos conjugados e 207 unidades de quarto e sala. Na década de 1970, o edifício mudou de numeração, passando a ser 194, como meio de fugir ao estigma associado à má fama já então conhecida em toda a cidade. Sobre a mudança de numeração, o escritor João Antonio disse: "Mudaram o número do 200. Mas ele continua o velho 200 da Rua Barata Ribeiro, um dos crimes mais consideráveis da nossa construção civil. E um dos pontos mais críticos a que pode chegar a chamada civilização do quarto-e-sala" (2001:65).

5. Gilberto declara ter vivido em Copacabana dos 6 aos 24 anos de idade (de 1952 a 1970), após passar a primeira infância no Grajaú, bairro de classe média localizado na zona norte do Rio de Janeiro. Diz ainda que se lembra do tom orgulhoso com que anunciava aos seus professores e colegas que estava de mudança para Copacabana.

6. Cf. Weber, Max, "A objetividade do conhecimento na Ciência Social e na Ciência Política", "A ciência como vocação" e "O sentido da neutralidade axiológica nas ciências políticas e sociais".

7. Enquanto a cidade do Rio de Janeiro observou um crescimento populacional de $240 \%$ entre os anos de 1920 e 1970, a população de Copacabana cresceu nada menos que $1.500 \%$ no mesmo período.

8. Para uma reflexão sobre a história e a construção social do prestígio do bairro de Copacabana, ver O’Donnell, Julia. A invenção de Copacabana (2013).

9. Em entrevista dada em 2010, Gilberto Velho afirma que "lendo Malinowski, lendo EvansPritchard, lendo Leach, modestamente, o que eu queria era entender a cultura, a visão de mundo de um setor da sociedade brasileira" (http://www.ncpam.com.br/2010/11/autorretrato-degilberto-velho.html. Acesso em: 30/07/2013).

10. C. Wright Mills publicou, em 1951, um estudo sobre a classe média americana com o título White Collar: The American Middle Classes.

11. De acordo com Clifford Geertz (1989:143-4), "Na discussão antropológica recente, os aspectos morais (e estéticos) de uma dada cultura, os elementos valorativos, foram resumidos sob o termo ethos, enquanto os aspectos cognitivos, existenciais, foram designados pela expressão 'visão de mundo'. O ethos de um povo é o tom, o caráter e a qualidade de sua vida, seu estilo moral e estético e sua disposição; é a atitude subjacente em relação a ele mesmo e ao seu mundo que a vida reflete. A visão de mundo que esse povo tem é o quadro que elabora das coisas como elas são na simples realidade, seu conceito de natureza, de si mesmo, da sociedade".

12. A UNE, União Nacional dos Estudantes, teve sua sede incendiada por tropas militares no dia do golpe militar de 1964, como forma de intimidação dos estudantes que se opunham à instauração do novo regime.

13. De acordo com Gilberto Velho, "evitando um voluntarismo individualista agonístico ou um determinismo sociocultural rígido, as noções de projeto e de campo de possibilidades podem ajudar na análise de trajetórias e biografias enquanto expressão de um quadro sócio-histórico, sem esvaziá-las arbitrariamente de suas peculiaridades e singularidades” (1994:40).

14. "Homenagem a Gilberto Velho". 2012. Mana, 18(1):173-212. 


\section{RESUMOS}

$\mathrm{O}$ artigo parte da publicação do texto inédito de Gilberto Velho e Yvonne Maggie sobre o Barata Ribeiro 200, neste número do Anuário Antropológico, para fazer uma reflexão acerca dos primórdios da Antropologia Urbana no Brasil. Tomando como ponto de partida a centralidade da obra de Gilberto Velho neste campo, o artigo retoma seu primeiro livro autoral, A utopia urbana, de modo a buscar ali as bases da longa trajetória de seu autor, bem como as evidências de um projeto mais amplo de consolidação da Antropologia Urbana no país.

The paper begins with the publication of Gilberto Velho and Yvonne Maggie's research on Barata Ribeiro 200, in this issue of the Anuário Antropológico, to analyze the beginnings of Urban Anthropology in Brazil. Considering Gilberto Velho's centrality in this field, the paper goes back to his first book, A utopia urbana, in order to search for the foundations of the central concepts developed by the author in further works, as well as evidences of a broader project on the consolidation of urban anthropology in the Brazil.

\section{ÍNDICE}

Keywords: urban anthropolgy, Gilberto Velho, Copacabana, ethnography

Palavras-chave: antropologia urbana, Copacabana, Gilberto Velho, etnografia

\section{AUTOR}

\section{JULIA O'DONNELL}

CPDOC/FGV Julia O'Donnell é professora adjunta da Escola de Ciências Sociais do Cpdoc/FGV. Atua na interface entre a História e a Antropologia Urbana, e é autora de De olho na rua: a cidade de João do Rio (Zahar, 2008) e A invenção de Copacabana (Zahar, 2013). Contato: julia@fgv.br 